\title{
Unexpected catalytic activity of the regulatory protein QacR
}

\author{
Cora Gutiérrez de Souza, Lur Alonso-Cotchico, Manuela Bersellini Gerard Roelfes * \\ Stratingh Institute for Chemistry, University of Groningen, Nijenborgh 4, 9747 AG Groningen (The Netherlands) \\ E-mail: j.g.roelfes@rug.nl
}

\begin{abstract}
Natural proteins often present binding or functional promiscuity. In biocatalysis, this promiscuity has been exploited for accessing newto-nature reactions. Here, we report an unexpected catalytic activity for the regulatory protein QacR from the TetR family of Multidrug Resistance Regulators. QacR_C72A_C141S is able to catalyze the tandem Friedel-Crafts/enantioselective protonation of indoles with $\alpha$-substituted conjugated enones with $38 \%$ yield and up to $83 \%$ ee. Mutagenesis and computational studies support the hypothesis that an acidic residue in the binding pocket of the protein is responsible for protonating the reaction intermediate.
\end{abstract}

In the quest for biocatalysis of abiotic reactions, an attractive approach involves taking advantage of enzyme catalytic promiscuity. ${ }^{1}$ Basal levels of activity different than the native one confer enzymes the ability to adapt to environmental changes. ${ }^{2}$ In enzyme engineering, this characteristic is exploited to create enzymes for new reactions by applying rational, computational or directed evolution techniques. ${ }^{3,4} \mathrm{~A}$ common approach is repurposing existing proteins that exhibit some level of promiscuity in substrate binding or activity to enable new-to-nature reactions. Such an approach is well illustrated by heme-dependent enzymes like P450s. ${ }^{5,6}$ The use of xenobiotic substrates allowed these proteins to access a wide range of unnatural reactions with high turnover numbers. ${ }^{5}$ Basal levels of catalytic activity for abiological transformations can sometimes also be observed in proteins which natural function is not catalysis. For example, heme-containing proteins like myoglobin, have been shown to catalyze non-natural reactions. ${ }^{7,8}$ Similarly, bovine serum albumin (BSA) does not have any natural catalytic activity, however, the presence of a lysine residue, originally responsible for ligand binding, grants it low levels of catalytic activity for a range of abiotic reactions. ${ }^{9}$ Alternatively, pre-existing binding sites of proteins have been repurposed for binding external abiological catalytic cofactors and thus introduce different reactivities into their scaffolds. ${ }^{10}$ Here, we present a regulatory protein from the TetR family, QacR, that showed unexpected catalytic activity for the tandem Friedel-Crafts/enantioselective protonation reaction of an indole with an $\alpha$-substituted $\alpha, \beta$-unsaturated thiazole.

Multidrug resistance regulators (MDRs) are a type of proteins involved in regulating efflux pump expression for antibiotic resistance. Their natural function grants these proteins the ability to bind structurally different aromatic planar drugs. In previous work, our group investigated the potential of the multispecificity of this class of proteins as a means for introducing catalytic activity into their scaffolds. ${ }^{11-13}$ A series of artificial metalloenzymes (ArMs), hybrid systems in which a metal complex was embedded into a biological scaffold to introduce abiotic reactivities, were created. Among the MDRs, a large amount of work has focused on the Lactococcal multidrug resistance regulator $(\mathrm{LmrR})$ protein from the PadR family. ${ }^{14,15}$ Recently, the repertoire of MDR scaffolds for ArMs was expanded to three proteins from the TetR family: CgmR, RamR and QacR. ${ }^{16}$ These three proteins proved their catalytic potential in the Friedel-Crafts (F-C) alkylation reaction of indoles with $\beta$-substituted $\alpha, \beta$-unsaturated 2 -acyl-imidazoles when introducing the metal-binding unnatural amino acid 2,2'bipyridylalanine (bpyAla) into their scaffolds ${ }^{13}$ or simply by using $\mathrm{Cu}\left(\mathrm{NO}_{3}\right)_{2}$ and an aromatic substrate without the need for a ligand to anchor the metal into the protein scaffolds. ${ }^{17}$

This inspired us to further explore the catalytic activity of CgmR, RamR and QacR in the tandem Friedel-Crafts/enantioselective protonation (F-C/EP) of indoles with $\alpha$-substituted conjugated enones. ArMs based on $\mathrm{DNA}^{18}$ and $\mathrm{LmrR}^{19}$ were reported previously for this reaction, which encouraged the investigation of the F-C/EP with these TetR proteins and $\mathrm{Cu}^{2+}$ ions. In this reaction, the stereochemical center is not created in the conjugate addition step, but in the subsequent protonation. This presents several challenges which are related to the small size of protons and their high mobility, especially in aqueous media, which makes them difficult to control and makes it hard to achieve kinetic control over the protonation step. ${ }^{20-22}$

The ArMs were self-assembled by incubation of QacR, CgmR or RamR with $\mathrm{Cu}\left(\mathrm{NO}_{3}\right)_{2}$. A double mutant of QacR (C72A and C141S) was used to avoid disulfide bonds and simplify the protein production protocol. ${ }^{23}$ The ArMs were then tested in the conjugate addition of 2-methyl- $1 \mathrm{H}$-indole (2) to 2-methyl-1(thiazol-2-yl)prop-2-en-1-one (1) (Table 1). The reactions were performed at $\mathrm{pH} 7.0$ or 5.0. Experiments without protein and $\mathrm{Cu}\left(\mathrm{NO}_{3}\right)_{2}$, or with only $\mathrm{Cu}\left(\mathrm{NO}_{3}\right)_{2}$ did not give rise to product formation (entries 1, 2, 12, 13). At pH 7.0, using only protein led to low yields and enantioselectivities (entries 4, 7, 10). The combination of protein with $\mathrm{Cu}\left(\mathrm{NO}_{3}\right)_{2}$ resulted in increased yields of product 3 , with a moderate ee of $54 \%$ in case of RamR (entry 3 ) and $42 \%$ ee, for the opposite enantiomer, in case of QacR (entry 6). Decreasing the $\mathrm{pH}$ to 5.0 led to an increase of the enantioselectivity to $77 \%$ in case of $\mathrm{Cu}^{2+} \subset$ QacR (entry 14). CgmR and RamR partially precipitated at this $\mathrm{pH}$ and this led to irreproducibility of the catalysis results. 
Table 1 Catalysis results for the FriedelCrafts/enantioselective protonation reaction.

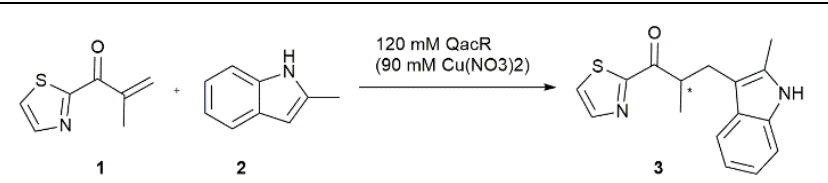

\begin{tabular}{lllll} 
Entry & catalyst & $\mathrm{pH}$ & Yield (\%) & ee (\%) \\
& & & & \\
\hline 1 & - & 7.0 & $<5$ & n.d. \\
2 & $\mathrm{Cu}^{2+}$ & 7.0 & $<5$ & n.d. \\
3 & $\mathrm{Cu}^{2+} \subset$ RamR & 7.0 & $24 \pm 4$ & $54 \pm 5$ \\
4 & RamR & 7.0 & $15 \pm 5$ & $-13 \pm 10$ \\
$5^{\mathrm{a}}$ & RamR & 7.0 & $12 \pm 8$ & $4 \pm 9$ \\
6 & $\mathrm{Cu}^{2+} \subset \mathrm{QacR}$ & 7.0 & $31 \pm 5$ & $-42 \pm 8$ \\
7 & QacR & 7.0 & $13 \pm 9$ & $9 \pm 3$ \\
$8^{\mathrm{a}}$ & QacR & 7.0 & $15 \pm 7$ & $10 \pm 3$ \\
9 & $\mathrm{Cu}{ }^{2+} \subset \mathrm{CgmR}$ & 7.0 & $15 \pm 1$ & $-4 \pm 2$ \\
10 & $\mathrm{CgmR}$ & 7.0 & $13 \pm 6$ & $-1 \pm 4$ \\
$11^{\mathrm{a}}$ & $\mathrm{CgmR}$ & 7.0 & $13 \pm 10$ & $-5 \pm 9$ \\
12 & - & 5.0 & $<5$ & $\mathrm{n} . \mathrm{d}$. \\
13 & $\mathrm{Cu}{ }^{2+}$ & 5.0 & $<5$ & $\mathrm{n} . \mathrm{d}$. \\
14 & $\mathrm{Cu}{ }^{2+} \subset \mathrm{CacR}$ & 5.0 & $26 \pm 3$ & $-77 \pm 4$ \\
15 & QacR & 5.0 & $38 \pm 9$ & $-75 \pm 4$ \\
$16^{\mathrm{a}, \mathrm{b}}$ & QacR & 5.0 & $40 \pm 6$ & $-83 \pm 0$
\end{tabular}

Typical reaction conditions employed: $120 \mu \mathrm{M}$ of QacR (dimer), $90 \mu \mathrm{M}$ of $\mathrm{Cu}\left(\mathrm{NO}_{3}\right)_{2}$ and $1 \mathrm{mM}$ of substrates $\mathbf{1}$ and $\mathbf{2}$ in 20 mM MES buffer $\mathrm{pH} 5.0$ or MOPS buffer $\mathrm{pH} 7.0,500 \mathrm{mM} \mathrm{NaCl}$, at $4{ }^{\circ} \mathrm{C}$ for $72 \mathrm{~h}$. The results are average of two independent experiments each of them performed in duplicate. Sign of ee indicates the order of elution on chiral HPLC with + corresponding to the firsteluting enantiomer in excess. aProtein previously incubated with EDTA and subsequently submitted to dialysis against the reaction buffer. ${ }^{b}$ Average of two independent experiments.

Surprisingly, at $\mathrm{pH} 5.0$ the reaction in presence of QacR without $\mathrm{Cu}\left(\mathrm{NO}_{3}\right)_{2}$ led to similar ee of $75 \%$ and an increased yield (38\%). To ensure that no other metal ions were present in the reaction mixture, which could be responsible for the catalytic activity observed, the reactions were repeated after incubation of the proteins with $50 \mathrm{mM}$ EDTA and double dialysis against 1:1000 $20 \mathrm{mM}$ MES, $500 \mathrm{mM} \mathrm{NaCl}, \mathrm{pH}$ 5.0. No loss of activity was observed for any of the proteins, and a further small increase in enantioselectivity to $83 \%$ for QacR at $\mathrm{pH} 5.0$ was obtained (entries 5, 8, 11 and 16; and Table S3).

The fact that wild-type QacR by itself, without any added metal ions, showed an inherent activity for catalysis of the F-C/EP reaction is a striking finding. In nature, enzymes such as decarboxylases and esterases use interactions of a combination of amino acid residues to both activate a prochiral proton acceptor and act as proton donor to effectively perform enantioselective protonations. ${ }^{21}$ We hypothesized that, analogous to natural enzymes, an acidic amino acid residue of the protein could be responsible for effectively protonating the prochiral $\mathrm{C} \alpha$ of the reaction intermediate following a Brønsted acid catalyzed mechanism.
To gain further insights into the mechanism, the effect of the $\mathrm{pH}$ in the reaction was investigated. The F-C/EP reaction was performed in a range of $\mathrm{pH}^{\prime} \mathrm{s}$ with QacR in presence and absence of $\mathrm{Cu}\left(\mathrm{NO}_{3}\right)_{2}$. The data obtained showed a correlation between $\mathrm{pH}$ and both activity and selectivity in the reaction performed with QacR alone. A decrease of $\mathrm{pH}$ translated into an increase of yield and ee, with pH 5.0 being optimal (see Fig. 1 and Table S4). This result was attributed to the relation between the protonation state of the proton donor amino acid and the proton transfer efficiency to the enolate intermediate. Moreover, the pronounced increase in ee at $\mathrm{pH} 5.0$ indicates that at this $\mathrm{pH}$ the enantioselective protonation happens preferably via one of the two prochiral faces of the enolate

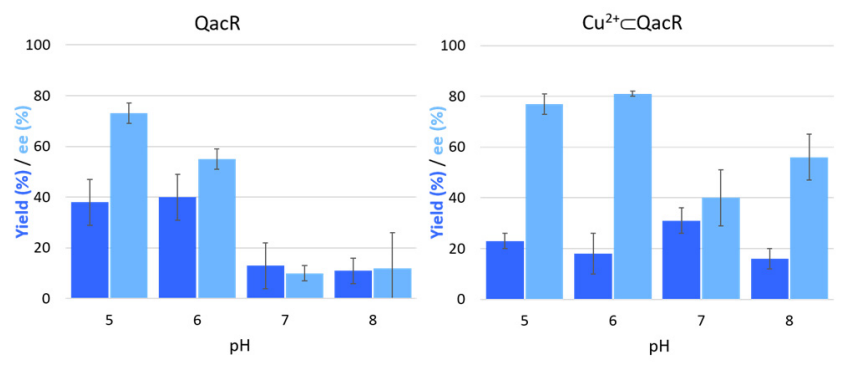

Fig. 1 Effect of $\mathrm{pH}$ in QacR and $\mathrm{Cu}^{2+} \subset \mathrm{Q} a c R$ for the Friedel-rafts/enantioselective protonation reaction. Typical conditions: $120 \mu \mathrm{M}$ QacR, $90 \mu \mathrm{M} \mathrm{Cu}\left(\mathrm{NO}_{3}\right)_{2}$ (when applicable), $1 \mathrm{mM} 1$ and 2, in $20 \mathrm{mM}$ MES buffer for pH 5.0 and 6.0 or $20 \mathrm{mM}$ MOPS buffer for $\mathrm{pH} 7.0$ and 8.0., containing $500 \mathrm{mM} \mathrm{NaCl}$, at $4{ }^{\circ} \mathrm{C}$ for $72 \mathrm{~h}$. The results are average of at least two independent experiments, each of them performed in duplicate.

intermediate. On the other hand, the effect of $\mathrm{pH}$ on the $\mathrm{Cu}^{2+} \subset \mathrm{QacR}$ system was less clear. No significant trend in activity was observed in the $\mathrm{pH}$ range investigated. Higher enantioselectivities were observed at acidic $\mathrm{pHs}$, but the ee was still significant at neutral or slightly basic pH (Fig. 1). Notably, at $\mathrm{pH}>5$ the ee was generally higher for the reaction catalyzed by $\mathrm{Cu}^{2+} \subset \mathrm{QacR}$ compared to QacR alone. The different effect of $\mathrm{pH}$ in the reaction with QacR in presence or absence of $\mathrm{Cu}\left(\mathrm{NO}_{3}\right)_{2}$, suggested that the reaction can follow two pathways, which are either catalyzed by the protein alone, or by $\mathrm{Cu}^{2+}$ embedded in the protein, as reported before for the Friedel-Crafts reaction. ${ }^{17}$

We inspected the crystal structure (PDB 1JTY) to identify residues that could be playing a role in donating a proton to the $\mathrm{C} \alpha$ of the enolate intermediate. Initially, three potential proton donors (Tyr103, Tyr123 and Glu120) were identified in the binding pocket of QacR and their pKa's in the environment of the protein were calculated using the PROPKA algorithm, included in the Chimera software. Tyrosines 103 and 123, with pKa $=16.0$ and 14.2 respectively, were discarded as possible proton donors, since their pKa's were too high to explain a difference in the protonation state between $\mathrm{pH} 5$ and 7 . In contrast, a pKa of 7.8 was calculated for Glu120, meaning that this residue would be fully protonated at $\mathrm{pH} 5.0$, whereas at $\mathrm{pH}$ 7.0 it would only partially be protonated. Thus, Glu120 could potentially act as Brønsted acid at lower $\mathrm{pH}$ explaining the higher activities and selectivities observed at $\mathrm{pH} 5$ and 6 compared to $\mathrm{pH} \geq$ 7. To investigate this hypothesis further, we mutated glutamic acid 120 to glutamine (E120Q), to maintain a similar size of the side chain and remove the acidic character. The mutant QacR_E120Q showed a similar yield (24\%) compared to QacR, 
but a complete loss of ee (see Scheme 1 and Table S6). This finding supports the hypothesis of Glu120 acting as Brønsted acid for the enantioselective protonation step at $\mathrm{pH} 5.0$ as well as that it suggests that the reaction is taking place inside the hydrophobic pocket of QacR. In addition, the presence of $\mathrm{Cu}\left(\mathrm{NO}_{3}\right)_{2}$ in the reaction with QacR_E120Q showed a comparable yield (26\%) but an increase of the enantiomeric excess (22\%) compared to that of QacR_E120Q without $\mathrm{Cu}^{2+}$. These results suggested that $\mathrm{Cu}^{2+}$ bound to the thiazole substrate 1 could be driving the reaction to happen within the protein scaffold (and hence in an enantioselective manner), since as shown in our previous work with $\mathrm{Cu}^{2+} \subset \mathrm{QacR}$ for the Friedel-Crafts reaction. ${ }^{17}$ a)

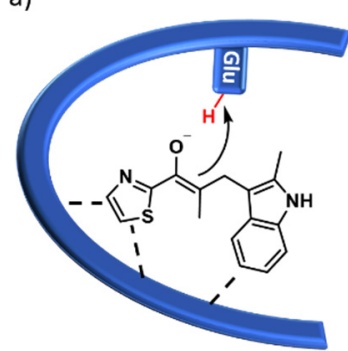

b)

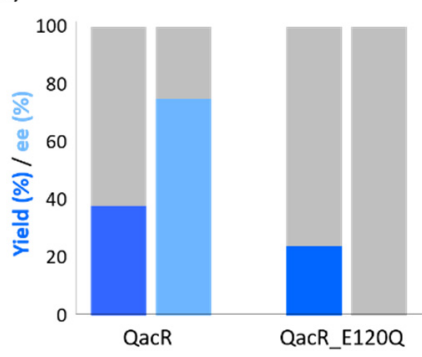

(conjugate addition of the indole) and TS2 (protonation by Glu120) of the reaction mechanism to occur without significant structural rearrangements of the intermediate (Fig. 2b and S9).

These results support the analysis from the experimental findings, suggesting Glu120 as a possible catalytic residue able to protonate the enolate intermediate of the F-C/EP reaction. The fact that pre-catalytic conformations were not highly represented during the MD simulation time scale, could explain why this system shows good enantioselectivity at $\mathrm{pH}$ 5.0, but only moderate yield.

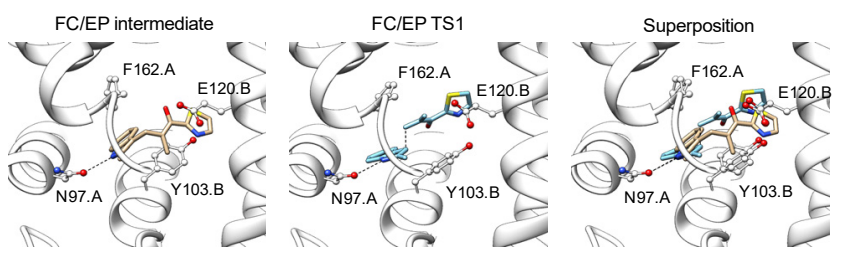

Fig. 2 Docking of the FC/EP intermediate (left) and the transition state structure of the first step of the reaction TS1 (center).

In conclusion, we showed that QacR, a regulatory protein from the TetR family of multidrug resistance regulators with no natural catalytic function, exhibits unexpected catalytic activity for the Friedel-Crafts/enantioselective protonation reaction of 2 -methyl indole with an $\alpha$-substituted $\alpha, \beta$-unsaturated 2-acyl thiazole achieving moderate yield (38\%) and good enantiomeric excess, up to $83 \%$ ee, without requiring a metal cofactor. Mutagenesis and computational studies suggest the role of Glu120 in protonating the prochiral reaction intermediate and, thus, acting as Brønsted acid. Overall, these findings provide a new example of the potential of exploiting binding multispecificity of natural proteins as a source of new-to-nature reactivities.

Financial support from the Netherlands Organisation for Scientific Research (NWO, Vici grant 724.013.003) and the European Research Council (ERC starting grant no. 280010) is gratefully acknowledged. G.R. acknowledges support from the Ministry of Education Culture and Science (Gravitation programme no. 024.001.035). (Fig. S7b,c). These interactions were consistent with those found for the protein bound to ethidium bromide (ETB), which has been reported to bind within the pocket of QacR with a binding constant of $2.35 \mu \mathrm{M}^{24}$ (Fig. S7a). A clustering analysis of the MD simulation revealed three major binding modes of the intermediate into the active site, grouped into clusters $\mathrm{c0}, \mathrm{c} 1$ and $\mathrm{c} 2$. Cluster $\mathrm{c} 1$ showed structures in which the intermediate was displaced along the tunnel of the QacR active site; this would not permit catalysis to occur. Therefore, $c 1$ was not taken into consideration. While for cluster c0 (33\% of the simulation snapshots), structures that could allow catalysis according to our hypothesis were not found (Fig. S7b), the binding modes in c2 ( $15 \%$ of the MD simulation snapshots) showed orientations of the intermediate in which C $\alpha$ could be protonated by Glu120 (Fig. S7c). To assess whether the binding mode of this intermediate was also suitable for the conjugate addition step (TS1) of the reaction, TS1 was also docked into the active site (Fig. S8b). The data obtained suggested that the geometries of both TS1 and the enolate intermediate can fit in the active site in a similar arrangement that would allow both steps TS1

\section{Notes and references}

H. Renata, Z. J. Wang and F. H. Arnold, Angew. Chem. Int. Ed., 2015, 54, 3351-3367.

O. Khersonsky and D. S. Tawfik, Annu. Rev. Biochem., 2010, 79, 471-505.

I. Nobeli, A. D. Favia and J. M. Thornton, Nat. Biotechnol., 2009, 27, 157-167.

R. B. Leveson-Gower, C. Mayer and G. Roelfes, Nat. Rev.

Chem., 2019, 3, 687-705.

O. F. Brandenberg, R. Fasan and F. H. Arnold, Curr. Opin.

Biotechnol., 2017, 47, 102-111.

P. S. Cohelo, E. M. Brustad, A. Kannan and F. H. Arnold,

Science, 2012, 3747, 307-311.

M. Bordeaux, V. Tyagi and R. Fasan, Angew. Chem. Int. Ed., 2015, 54, 1744-1748.

M. Bordeaux, R. Singh and R. Fasan, Bioorg. Med. Chem., 2014, 22, 5697-5704. 
D. C. M. Albanese and N. Gaggero, RSC Adv., 2015, 5, 1058810598.

Y. Okamoto, V. Köhler, V. Lebrun, R. Reuter, T. R. Ward, F.

Chem. Rev., 2017, 118, 142-231.

11 J. Bos, F. Fusetti, A. J. M. Driessen and G. Roelfes, Angew.

Chem. Int. Ed., 2012, 51, 7472-7475.

12 L. Villarino, K. E. Splan, E. Reddem, L. Alonso-Cotchico, C.

Gutiérrez de Souza, A. Lledós, J.-D. Maréchal, A.-M. W. H.

Thunnissen and G. Roelfes, Angew. Chemie Int. Ed., 2018, 57, $7785-7789$.

13 M. Bersellini and G. Roelfes, Org. Biomol. Chem., 2017, 15, 3069-3073.

14 G. Roelfes, Acc. Chem. Res., 2019, 52, 545-556.

15 P. K. Madoori, H. Agustiandari, A. J. M. Driessen and A.-M. W.

H. Thunnissen, EMBO J., 2009, 28, 156-166.

16 J. L. Ramos, M. Martinez-Bueno, A. J. Molina-Henares, W. Teran, K. Watanabe, X. Zhang, M. T. Gallegos, R. Brennan and

R. Tobes, Microbiol. Mol. Biol. Rev., 2005, 69, 326-356.

17 C. Gutiérrez de Souza, M. Bersellini and G. Roelfes, ChemCatChem, 2020, 12,3190-3194.

18 A. García-Fernández, R. P. Megens, L. Villarino and G. Roelfes, J. Am. Chem. Soc., 2016, 138, 16308-16314.

19 L. Villarino, S. Chordia, L. Alonso-Cotchico, E. R. Reddem, A.M. Thunnissen, J.-D. Maréchal and G. Roelfes, ChemRxiv, Prepr., , DOI:10.26434/chemrxiv.11969o10.

20 J. P. Phelan and J. A. Ellman, Beilstein J. Org. Chem., 2016, 12, 1203-1228.

21 J. T. Mohr, A. Y. Hong and B. M. Stoltz, Nat. Chem., 2009, 1, 359-369.

22 C. Fehr, Angew. Chemie - Int. Ed., 1996, 35, 2566-2587.

23 S. Grkovic, M. H. Brown, M. A. Schumacher, R. G. Brennan and R. A. Skurray, J. Bacteriol., 2001, 183, 7102-7109.

24 K. M. Peters, B. E. Brooks, M. A. Schumacher, R. A. Skurray, G. Richard, M. H. Brown, R. G. Brennan and M. H. Brown, PLoS One, 2011, 6, e15974. 